\title{
The Efficiency of Hamilton Pretest Probability Value in Diagnosing Deep Vein Thrombosis
}

\author{
Starry Homenta Rampengan \\ Department of Cardiology and Vascular Medicine, Faculty of Medicine, Sam Ratulangi University, Manado, Indonesia
}

Email address:

starry8888@yahoo.com

To cite this article:

Starry Homenta Rampengan. The Efficiency of Hamilton Pretest Probability Value in Diagnosing Deep Vein Thrombosis. Clinical Medicine Research. Vol. 4, No. 2, 2015, pp. 43-49. doi: 10.11648/j.cmr.20150402.14

\begin{abstract}
Deep vein thrombosis (DVT) is a condition, in which an obstruction of blood flow in veins is found due to the formation of blood clots in the deep veins. An objective diagnosis of DVT is based on ultrasonography examination. However, in poor countries, including Indonesia, many hospitals still do not have the facilities of ultrasonography, less vascular specialists, or D-dimer examination and therefore, to establish the diagnosis of DVT they only can rely on history taking and physical examination. To find out whether the high Hamilton PPS can be used to diagnosis of DVT and whether the high Hamilton score the greater the possibility for DVT, and to know it sensitivity and specificity. A cross-sectional study was done, which was conducted to identify the reliability (sensitivity and specificity) of Hamilton PPS in establishing DVT diagnosis. The study used the Color Duplex Sonography (CDS) for extremity veins as the gold standard. We enrolled 193 patients with probability of DVT. Hamilton PPS and extremity veins CDS were done and tabulation was performed and data was analyzed statistically. Data analysis for testing was performed by the logistic regression analysis and Receiver Operating Characteristic curve using a computer software program of SPSS version 17.0. Hamilton score has sensitivity 0.8 , specificity 0.85 , accuracy of value 0.84 and positive predictive value 0.63 , negative predictive value 0.93 . The correlation between Hamilton score and sonography to diagnosis of DVT is positive with the sensitivity and specificity of Hamilton score is $\geq 80 \%$.
\end{abstract}

Keywords: Color Duplex Sonography, Deep Vein Thrombosis, Extremity Veins, Hamilton Score, Sensitivity, Specificity

\section{Introduction}

Deep vein thrombosis (DVT) has an estimated annual incidence of 67 per 100,000 among the general populations. ${ }^{1}$ Untreated deep vein thrombosis is a high risk factor to develop pulmonary embolism that causes death in $5-10 \%$ hospitalized patients with DVT and also the highest leading cause of death during pregnancy. ${ }^{2-4}$ These facts have become the principles of prompt DVT diagnosis so that the appropriate treatment can be provided in order to reduce the complication of thromboembolism.

Some other risk factors that must be considered on the possibility of developing DVT are history of previous DVT or pulmonary embolism, elderly age, the presence of malignant disease, immobilization such as casting on the lower extremities, history of recent trauma on the lower extremities, history of DVT in the family, pregnancy, using oral contraception, history of bed rest more than 3 days or history of having surgery in the last 4 weeks and other risk factors. ${ }^{4-9}$ Deep vein thrombosis is most frequently found in lower extremities and the most common clinical manifestation is lower extremity edema, i.e. the pitting edema, which is usually unilateral with a localized tenderness and a firm palpation as a result of venous stasis, calf circumference which is $3 \mathrm{~cm}$ larger than the normal calf, redness with high skin temperature along with superficial and cyanotic venous dilatation if there is a total venous obstruction. ${ }^{10-15}$

Lower extremity and pelvis are body parts that mostly have DVT. ${ }^{16-18}$ History taking on risk factors and clinical manifestation will be very helpful to identify the possibility of DVT before any radiologic examination can be performed. Based on the history taking and physical examination to identify the development of DVT, an assessment was established, which is known as the Pretest Probabilty Score (PPS). ${ }^{19,20}$

A PPS model is a score that evaluate risk factors of clinical manifestation to predict the possibility of DVT development, which will be very helpful for doctors in early risk stratification and appropriate use of laboratory tests and imaging modalities to increase the accuracy of DVT 
diagnosis. Patient stratification of DVT will be more accurate in those who had been evaluated with PPS..$^{19,20-22}$ Notoriously many pretest probability scoring systems are proposed for use in primary care patients, such as Wells score, Hamilton score, and AMUSE score, among which Wells score is the most studied. However, the modified Wells score has limitations in discriminating patients likely to have DVT and those unlikely to have DVT. In a study by Wells involving 1,096 ambulatory outpatients, 601 patients $(54.8 \%)$ were identified as unlikely to have DVT and 495 patients (45.2\%) as likely to have DVT, using Wells modified score the recent model for DVT PPS is the Hamilton PPS. The Hamilton pretest probability score is a PPS model equipped with a simple criteria and it is easily calculated. The Hamilton Probability Score has 7 components, including 6 objective components and 1 subjective component. ${ }^{19,23}$ Therefore, physicians deliver an intuitive judgment of a high risk of DVT without the possibility of another diagnosis. For this reason Hamilton's pretest scores more patients clearly identified in the unlikely category, which caused the Wells score change, and it was more predictive of DVT in the category likely to score Wells. In addition to PPS, another further work-up is D-dimer test; however, the test is not specific for DVT diagnosis. The potential value of D-dimer test is on its capacity to exclude diagnosis of DVT. A successful D-dimer implementation in clinical practice needs a high sensitivity and negative predictive value..$^{19,22,24}$

An objective diagnosis of DVT is based on ultrasonography examination, which will provide high specificity and sensitivity value compared to other examinations used for establishing the diagnosis of DVT. ${ }^{6,14,18}$ However, in poor countries, including Indonesia, many hospitals still do not have the facilities of ultrasonography, less vascular specialists, or D-dimer examination and therefore, to establish the diagnosis of DVT they only can rely on history taking and physical examination. In this situation, the role of PPS in DVT diagnosis is essential. If the Hamilton Probability Score is turned out to be a reasonably sensitive and specific method in predicting or even making DVT diagnosis, then it can be a tool for diagnosing DVT, which is easy to use, inexpensive and practically applicable for any settings. The background of our study was to identify the accuracy of assessment using Hamilton PPS in establishing DVT diagnosis prior to the ultrasonography examination.

The purpose of our study is to identify any positive correlation between PPS Hamilton and ultrasonography results of patients suspected with DVT or to identify whether the higher PPS Hamilton would bring higher probability of DVT and to recognize whether the sensitivity and specificity of Hamilton PPS in establishing DVT diagnosis for patients suspected with DVT are reasonably high values ( $\geq 80 \%$ ).

\section{Methods}

Our study was a diagnostic test with a cross-sectional approach, which was conducted to identify the reliability (sensitivity and specificity) of Hamilton PPS in establishing DVT diagnosis. The study used the Color Duplex Sonography (CDS) for extremity veins as the gold standard.

Samples of our study were recruited from The Prof. DR. R.D. Kandou Hospital, The Jade Cardiovascular Clinic, The Adventist Hospital and The Siloam Manado Hospital. Samples were patients hospitalized in the ward of Department of Internal Medicine, Department of Surgery and Neurology. Patients with risk factors for DVT were interviewed for history taking and examined. Subsequently, the Hamilton PPS was calculated and ultrasonography examination was performed. CDS examination was done at the echocardiography unit in The Prof. DR. R.D. Kandou Hospital, The Jade Cardiovascular Clinic and The Siloam Manado Hospital. The study was conducted between August 2010 and August 2014.

The samples were retrieved from the population by consecutive sampling until the number of desired samples was achieved, i.e. 193 patients. The samples included patients who were suspected with DVT, who were hospitalized in The Prof. DR. R.D. Kandou Hospital, The Adventist Hospital or The Siloam Manado Hospital at the ward of Department of Internal Medicine, Department of Neurology and Department of Surgery and who were willing to participate in the study as well as who had met the inclusion. The inclusion criteria were patient with malignancy, immobilization using lower extremity cast in the last 4 weeks, recent trauma of extremities, history of previous DVT or pulmonary embolism, pregnant, using oral contraceptive pills or hormone therapy, history of bed rest more than 3 days or history of previous surgery in the last 4 weeks, obesity, lower extremity paralysis, history of surgery lasting more than 30 minutes, hypercholesterolemia, smokers, the presence of other severe concomitant diseases such as heart failure and sepsis. Patients were excluded if they were being received anticoagulant treatment or if they rejected to signed informed consent. The protocol was approved by the ethics committee of the Prof. DR. R.D. Kandou Hospital and Siloam Hospital Manado.

The study includes the participants for the two separate diagnostic procedures, d-dimer and CDS Sonography (gold standard). The patients did not pay anything in this study. The study was conducted in 3 stages. The first stage was patient selection including history taking and examination of patients who were hospitalized in The Prof. DR. R.D. Kandou Hospital, The Adventist Hospital and The Siloam Manado Hospital at the ward of Department of Internal Medicine, Department of Surgery and Department of Neurology. Patients who have met the criteria of our study were given explanation about the study and when they agreed to be the samples of our study, they were asked to sign the informed consent form. In the second stage, Hamilton PPS and extremity veins CDS were calculated; while in the third stage, tabulation was performed and data was analyzed statistically.

The data of our study was presented in tables and graphs. Data analysis for testing the hypothesis was performed by the logistic regression analysis and Receiver Operating 
Characteristic (ROC) curve using a computer software program of SPSS version 17.0. To calculate the sensitivity and specificity, we used the $2 \times 2$ tables.

\section{Results}

There were 193 samples that met the inclusion criteria with characteristics of 78 male subjects $(40.4 \%)$ and 115 female subjects $(59.6 \%)$. Sample distribution based on age revealed that the age of study samples was between 15 years and 89 years, with mean age of 56.83 years and standard deviation(SD) of 15.58 tahun. Most subjects were found in 51-60 years age group with65 subjects that were followed by 61-70 years age group with 40 subjects, $41-50$ years age group with 22 subjects, 41-50 years and 71-80 years age groups with 21 subjects each, 81-90 years age group with 15 subjects, 15-20 years age group with 6 subjects and 21-31 years age group with 3 subjects.

Risk factors of the samples including history of bed rest more than 3 days or history of previous surgery in the last 4 weeks, which was found in 69 subjects $(35.8 \%$ ), age $>50$ years in 126 subjects $(65.3 \%)$, malignancy in 42 subjects $(21.8 \%)$, lower extremity paralysis in 18 subjects $(9.3 \%)$, history of surgery lasting more than 30 minutes in 14 subjects $(7.3 \%)$, the presence of other severe concomitant diseases such as heart failure and sepsis in 18 subjects $(9.3 \%)$, recent trauma of extremities in 12 subjects (6.2\%), smokers in 12 subjects $(6.2 \%)$, obesity in 6 subjects $(3.1 \%)$, hypercholesterolemia in 6 subjects $(3.1 \%)$, history of previous DVT or pulmonary embolism in 6 subjects $(3.1 \%)$, immobilization using lower extremity cast in the last 4 weeks was also found in 3 subjects $(1.6 \%)$.

\subsection{Sample Distribution Based on Hamilton PPS and CDS}

In our study, there were 59 subjects (30.6\%) with Hamilton PPS $\geq 3$ and 134 subjects (69.4\%) with Hamilton PPS $\leq 2$. Of 59 subjects with Hamilton PPS $\geq 3$, there were 37 subjects $(62.7 \%)$ who had positive results of CDS and 22 subjects $(37.3 \%)$ with negative CDS. Of 134 subjects with Hamilton PPS $\leq 2$, there were 9 subjects $(6.7 \%)$ with positive CDS and 125 subjects $(93.3 \%)$ with negative CDS results (Figure1).

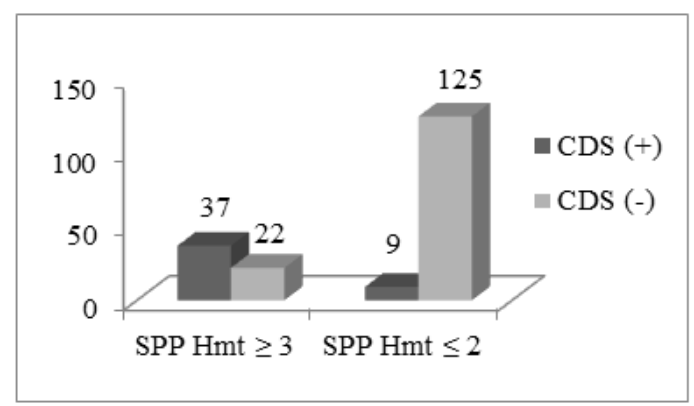

Figure 1. Sample distribution based on Hamilton PPS and CDS.

\subsection{Distribution of Risk Factors in Samples with DVT}

Risk factors found in 46 samples with DVT were history of bed rest more than 3 days or history of previous surgery in the last 4 weeks, which was found in 34 subjects $(73.9 \%)$, age $>50$ years was found in 33 subjects $(71.7 \%)$, malignancy was found in 19 subjects $(41.3 \%)$, recent extremities trauma in 6 subjects $(13.04 \%)$, extremity paralysis in 7 subjects $(15.2 \%)$, history of previous DVT or pulmonary embolism in 6 subjects $(13.04 \%)$, obesity in 3 subjects $(6.5 \%)$, history of surgery lasting more than 30 minutes was found in 3 subjects $(6.5 \%)$ and smokers were found 3 subjects $(6.5 \%)$ (Figure 2).

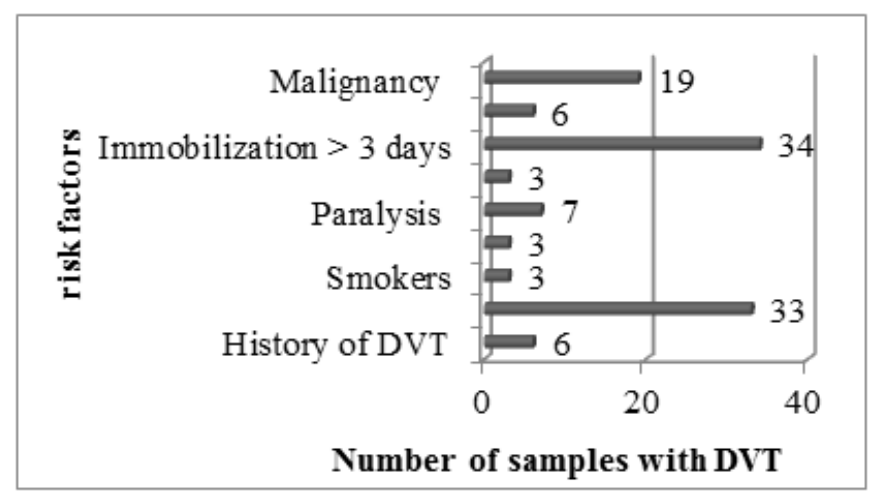

Figure 2. Distribution of risk factors in samples with DVT.

\subsection{The Correlation between Hamilton PPS and CDS}

In order to evaluate the level of correlation between Hamilton PPS and the probability of developing DVT and to identify whether high Hamilton PPS score would also increase the probability of having DVT, an analysis of logistic regression was used.

The correlation between each score of Hamilton PPS and the probability of developing DVT can be seen in the following table. (Table1).

Table 1. The correlation between Hamilton PPS score and the probability of developing $D V T$.

\begin{tabular}{ll}
\hline Hamilton PPS & The probability of developing DVT \\
\hline 0 & 0.01018 \\
1 & 0.04488 \\
2 & 0.17672 \\
3 & 0.49509 \\
4 & 0.81750 \\
5 & 0.95341 \\
\hline
\end{tabular}

The result of analysis using logistic regression test as has been mentioned above indicates that there was a very significant correlation between Hamilton PPS and DVT ( $p<$ 0.01). The higher Hamilton PPS, the greater probability of developing DVT in patients who were suspected with DVT.

\subsection{Sensitivity and Specificity of Hamilton PPS}

In order to identify the sensitivity and specificity of Hamilton PPS in establishing DVT diagnosis, we used the 2 $\mathrm{x} 2$ table (Table2). In the $2 \times 2$ table, there is true positive rate (A) in 37 subjects, false positive rate (B) in 22 subjects, false negative rate $(C)$ in 9 subjects and true negative rate $(D)$ in 125 subjects. 
Table 2. Correlation between CDS and Hamilton PPS (2 x 2 table).

\begin{tabular}{llll}
\cline { 1 - 3 } Hamilton Pretest & \multicolumn{2}{l}{ Color Duplex Sonography } & \multirow{2}{*}{ Total } \\
\cline { 1 - 3 } Probability Score & + & - & 59 \\
\hline$\geq 3$ & 37 & 22 & 134 \\
$\leq 2$ & 9 & 125 & 193 \\
Total & 46 & 147 & \\
\hline
\end{tabular}

Therefore, the sensitivity of Hamilton PPS for establishing diagnosis DVT in this study was:

$$
\frac{A}{A+C}=\frac{37}{37+9}=0.8
$$

and the specificity was $=$

$$
\frac{D}{B+D}=\frac{125}{22+125}=0.85
$$

with an accuracy of:

$$
\frac{A+D}{n}=\frac{37+125}{193}=0.84
$$

the positive predictive value was $=$

$$
\frac{A}{A+B}=\frac{37}{37+22}=0.63
$$

and the negative predictive value was $=$

$$
\frac{D}{C+D}=\frac{125}{9+125}=0.93
$$

Hamilton pretest probability score actually showed high sensitivity and specificity, which was $>80 \%$ in DVT diagnosis.

In order to obtain the cut-off point of Hamilton PPS for establishing the diagnosis of probable DVT in a patient, a diagnosis test was performed using an analysis based on ROC curve. In this analysis, Hamilton PPS became a test tool/ test variable and CDS became the gold standard to establish the diagnosis of DVT development.

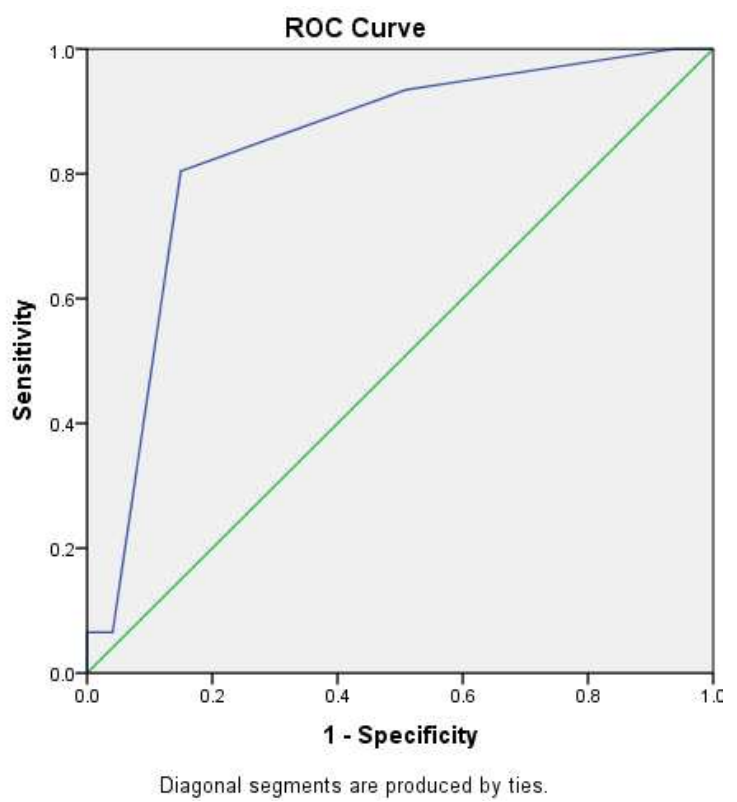

Figure 3. ROC Curve,
Based on the results of analysis using ROC curve (Figure 3), we found that the cut off point for Hamilton PPSwas 2.5. On the Hamilton PPS cut off point of 2.5, the following table was obtained (Table 3).

With the Hamilton PPS cut-off point of 2.5 (Table3), we found:

1. The sensitivity of Hamilton PPS to diagnose the development of DVT was $=80 \%$

2. The specificity of Hamilton PPS to diagnose the unlikely development of DVT was $=85 \%$

3. The positive predictive value of Hamilton PPSwas $=63 \%$

4. The negative predictive value of Hamilton PPSwas $=$ $93 \%$

5. The accuracy of Hamilton PPS was $=84 \%$

Table 3. Sensitivity and specificity of Hamilton PPSon 2.5 cut off point.

\begin{tabular}{llll}
\hline \multirow{2}{*}{ PPS Hamilton } & Positive & Negative & \multirow{2}{*}{ Total } \\
\cline { 2 - 3 }$>2.50$ & CDS & CDS & 59 \\
& $\begin{array}{l}37(80.4 \%)^{*} \\
(62.71 \%)^{* * *}\end{array}$ & $22(14.96 \%)$ & \\
$\leq 2.50$ & $9(19.56 \%)$ & $\begin{array}{l}125(85.03 \%)^{* *} \\
(93.38 \%)^{* * * *}\end{array}$ & 134 \\
Total & 46 & 147 & 193 \\
\hline
\end{tabular}

\section{Discussion}

Deep vein thrombosis occurs due to the presence of thrombus in vein, which according to the triad of Virchow it is a result of an abnormality in blood vessel, blood flow and alteration in coagulation capacity. ${ }^{25-30}$ The factors that have most important role in venous thrombosis are stasis and hypercoagulability. Risk factors that cause stasis and hypercoagulability will become predisposition factors for developing DVT. ${ }^{31-39}$

In a study evaluating 214 patients, which was conducted by Chou T, Subramaniam RM et al, there were 46 patients with DVT and 168 patients without DVT and the most significant variables associated with DVT were immobilization using cast, clinical suspicion made by the ER doctor that was very supportive for DVT diagnosis without any possibility for other diagnosis, malignancy, the presence of erythema manifestation, calf circumference more than 3 $\mathrm{cm}$, immobilization more than 3 days or recent surgery in the last 4 weeks and male subjects. ${ }^{19,23}$

In this study, there were 193 samples consisted of 78 (40.4\%) male subjects and 115 (59.6\%) female subjects with mean age of 56.83 years. The risk factors for developing DVT were history of immobilization more than 3 days or history of having recent surgery in the last 4 weeks, age over 50 years, malignancy, lower extremity paralysis, history of surgery that last more than 30 minutes, the presence of other severe concomitant disease such as heart failure and sepsis, recent trauma on the extremity, smoker, obesity, hypercholesterolemia, history of previous DVT or pulmonary embolism and immobilization using lower extremity cast in the last 4 weeks. All samples have more than two risk factors for developing DVT and the most common risk factors were age over 50 years, which was found in 126 subjects $(65.3 \%)$, 
history or immobilization more than 3 days or history of having recent surgery in the last 4 weeks found in 69 subjects $(35.8 \%)$ and malignancy found in 42 subjects $(21.8 \%)$.

Following the CDS examination for those 193 samples, we found 46 (49.46\%) samples with DVT and 147 (76.16\%) samples without DVT. Risk factors in the 46 samples with DVT were history of immobilization more than 3 days found in 34 subjects $(73.9 \%)$ and age more than 50 years found in 33 subjects $(71.7 \%)$, which were followed by malignancy in 19 subjects $(41.6 \%)$, lower extremity paralysis in 7 subjects $(15.2 \%)$, recent extremity trauma, history of DVT or pulmonary embolism found in 6 subjects (13.04\%) respectively, obesity, history of surgery that last more than 30 minutes and smokers found in 3 subjects $(6.5 \%)$ respectively. Thus, in this study, the most common risk factors for developing DVT were age over 50 years, bed rest more than 3 days and malignancy.

The male gender in this study apparently is not a significant risk factor for developing DVT since there was similar percentage between male subjects with DVT (41.3\%) and male subjects without DVT (40.1\%). Kahn et al believe that the correlation between male gender and DVT is vague since there are many affecting factors such as the number of female patients who visit the hospital may be less than male patients. ${ }^{20}$ In contrast, a study conducted by Subramaniam $\mathrm{RM}$ et al found that male gender is also a significant variable for developing DVT. ${ }^{19}$

In this study, the most common risk factor for DVT is immobilization more than 3 days, which was found in 34 subjects $(73.9 \%)$. Thrombosis in patients with immobilization occurs since the vein in immobilized extremity that tends to have slow blood flow, subsequently has even slower blood flow and causing stasis. The stasis causes disrupted clearance mechanism that may lead to accumulation of active coagulation factors and formation of thrombus in the area between vein wall and valve. ${ }^{27,29,40-42}$ The Score of Wells also put immobilization as a variable that must be calculated to determine the possibility of developing DVT. $^{20}$

The other most common risk factor for DVT found in this study was age over 50 years. It is consistent with a hypothesis suggesting that the thrombosis will occur when there is a "potency of thrombosis", which is an synergetic interaction between age, genetic and environment factors that has exceed certain threshold. ${ }^{29,40-47}$ A study conducted by Richard White also demonstrates that the age factor also has role in the incidence of DVT, which found 300 to 500 cases of DVT per 100,000 subjects aged 70-90 years compared to only 30 cases per 100,000 subjects aged 25 to 35 years. ${ }^{11}$ However, the study conducted by Subramaniam RM et al indicated that the age factor is not a significant variable for developing DVT and so does the study conducted by Wells and Kahn et al, which found that the risk of DVT is not increasing with age. ${ }^{23}$

The third most common risk factor found in this study was malignancy, i.e. 19 (41.3\%) subjects with DVT were found with concomitant malignancy. The type malignancy found in those 19 subjects were breast cancer in 6 subjects, rectal cancer, bladder and cervix cancers and chronic myelocytic leukemia were found in 3 subject for each cancer. Const an $\mathbf{J}$ et al and Wells et al found that cancer is also a significant risk factor for DVT. ${ }^{20}$ Patients with cancer have 4.1 times higher risk of thrombosis than those without cancer. Based on the study, it can be said that the highest risk of thrombosis is found in hematologic malignancy, which is followed by pulmonary and gastrointestinal cancer. Another study found that thrombosis in male subjects is commonly found in those with prostate, colon, pulmonary and brain cancer; while in female subjects, it is found in those with breast, pulmonary and ovarian cancer. ${ }^{29,45-49}$

Immobilization with cast, recent lower extremity trauma, surgery that last more than 30 minutes, smoking, hypercholesterolemia, paralysis, obesity, concomitant disease and history of previous disease prior to the DVT such as pulmonary embolism contributed only in small percentage in this study.

Based on the results of logistic regression analysis with $\mathrm{p}$ $=0.001$ and $\alpha=0.01$, we found that there was a correlation between Hamilton PPS and DVT; i.e. when the Hamilton PPS of a patient was $=0$, then the probability of DVT was 0.0101 and when the Hamilton PPS $=1$, then the probability of DVT was 0.0448 . The probability of developing DVT is increasing with the increasing score of Hamilton PPS. These results indicate that there is a very significant correlation or positive correlation between Hamilton PPS and the presence of DVT $(\mathrm{p}<0.01)$. It means that the probability of developing DVT will be higher when the Hamilton PPS score is increasing in patients with suspected DVT. The result is consistent with previous study conducted by Subramaniam RM et al that found significant correlation between 7 variables in PPS Hamilton and the development of DVT. ${ }^{19}$

Based on a study in 312 patients conducted by Rathan MS, Tina Chou et al, Hamilton PPS was found to be more accurate in identifying the possibility of DVT when it was compared to the score of Wells and they found that Hamilton score had $66.67 \%$ sensitivity, $71.14 \%$ specificity, $39.26 \%$ positive predictive value and $88.83 \%$ negative predictive value.

In this study, the sensitivity and specificity of Hamilton PPS to establish the diagnosis of DVT was determined using the $2 \times 2$ table (Table 2) and it is found that the sensitivity of Hamilton PPS was $80 \%$. These results subsequently confirmed the study conducted by Rathan MS, Tina Chou et al on the sensitivity and specificity of Hamilton PPS in establishing the diagnosis of DVT with sensitivity and specificity values of $>80 \%$.

If the results of this study were evaluated using ROC curve, a cut-off point of Hamilton PPS was found at score of 2.5. At the 2.5 Hamilton PPScut-off point, the senstivity was $80 \%$ and the specificity Hamilton PPSin diagnosing the unlikely occurence of DVT had been $>80 \%$. The cut-off of 2.5 extrapolated on the ROC curve, is the point where they balance greater sensitivity and specificity. Obviously in any patient such a score can be possible because the points awarded to the individual signs are unitary. We thinked that if 
the cut-off is better between 2 and 3 the system to assign scores should be re-evaluated, weighing differently the signs (so, we would say to edema barely half point, edema franc 1 point, etc). Basically a new study would be necessary to find out if a more sophisticated point system could improve the predictability of the score.

\section{Conclusion}

In this study, it can be concluded that there is a positive correlation between Hamilton PPS and results of so no graphy examination in patients suspected with DVT or the higher Hamilton PPS score in patients suspected with DVT, the higher probability of developing DVT; moreover, the sensitivity and specificity of Hamilton PPS for the development of DVT in patients suspected with DVT is relatively high $(\geq 80 \%)$.

\section{References}

[1] Scarvelis D, Wells PS. Diagnosis and treatment of deep-vein thrombosis. CMAJ 2006; 175(9):1087-92

[2] James AH. Venous Thromboembolism in Pregnancy. Arterioscler Thromb Vasc Biol. 2009;29:326-31

[3] Lapner ST, Kearon C. Diagnosis and management of pulmonary embolism. BMJ 2013;346: 7757

[4] Larson L, Mehta N, Miller M. Venous thromboemblic disease and pregnancy. N Engl J Med 2009;360:638-40

[5] Braekkan SK, Mathlesen EB, Njelstad I, et al. Hematocrit and risk of venous and thromboembolism in a general population. The Tromso study. Haematologica 2010;95:270-75

[6] Bates SM, Ginsberg JS. Treatment of deep-vein thrombosis. N Engl J Med 2004;351:268-77

[7] Bates SM, Jaeschke R, Stevens SM, Goodacre S, Wells PS, Stevenson MD, et al. Diagnosis of DVT: Antithrombotic Therapy and Prevention of Thrombosis, 9th ed: American College of Chest Physicians Evidence-Based Clinical Practice Guidelines. Chest 2012;141(2 Suppl):e351S-418S

[8] Francis CW. Prophylaxis for thromboembolism in hospitalized medical patients. N Engl J Med 2007;356:1438-44

[9] Hunt BJ. Grecr I. Low molecular weight heparin in pregnancy: current issues. British J of Haem 2004;128:593-601

[10] Mandala' M, Falanga A, Roila F. Management of venous thromboembolism (VTE) in cancer patients: ESMO Clinical Practice Guidelines. Annals of Oncology 2011; 22 (Suppl 6): vi85-vi92

[11] Cushman M. Epidemiology and Risk Factors for Venous Thrombosis. Semin Hematol 2007; 44(2):62-9.

[12] Goldhaber SZ. Venous thromboembolism: Epidemiology and magnitude of the problem. Best Practice \& Research Clinical Haematology 2012; 25 (3): 235-42

[13] Blom JW, Osanto S, Rosendaal FR. High risk of venous thrombosis in patients with pancreatic cancer: A cohort study of 202 patients. Eur J Cancer 2006;42:410-14
[14] McDonald DM, Yao LC, Baluk P. Dynamics of airway blood vessels and lymphatics: lessons from development and inflammation. Proc Am Thorac Soc 2011;8(6):504-7

[15] Cheng A, Scholtt DW. Care of hospitalized patient. In: Cheng A, Zaas A. The Osler Medical Handbook. The Curtis Center, Philadelphia.2004:57-63

[16] Longmore M, Rajagopalan S, Wilkinson I. Deep vein thrombosis. In: Oxford Handbook of Clinical Medicine. $6^{\text {st }}$ ed. Oxford University Press, New York. 2004:456-457

[17] Andritsos L, Eby C, Yusen RD. Disorders of hemostatis. In: The Washington Manual of Medical Therapeutics. $3^{\text {st }}$ ed. Lippincott Williams dan Wilkins, Washington. 2004;398-422

[18] Rizal ADI. Pengaruh pemberian heparin intravena sebagai profilaksis deep vein thrombosis terhadap kadar fibrinogen. Undip Semarang, 2012

[19] Subramaniam RM, Chou T, Heath R, et al. Importance of pretest probability score and D-dimer assay before sonography for lower limb deep venous thrombosis. AJR 2006;186:206-12

[20] Hunt Dan. Determining the clinical probability of deep venous thrombosis and pulmonary embolism. Southern Med J 2007; 100:1015-20

[21] Mal S, Mensah A, Smith C, et al. Is pretest probability assesment on emergency departmen patients with suspected venous thromboembolism documented before Simpli RED Ddimer testing?. N Engl J Med 2008;10:519-23

[22] Setiabudy RD. Pemeriksaan laboratorium pada thrombosis vena dalam. In: Setiabudy RD (ed). Hemostatis dan thrombosis. Edisi IV. Balai Penerbit FKUI, Jakarta. 2009:6677

[23] Heath R, Sleigh J, Subramaniam RM, et al. Diagnosis of lower limb deep venous thrombosis in emergency department patients: performance of Hamilton and modified Wells scores. Annals of Emergency Med 2006;48:678-85

[24] Cosmi B, Legnani C, Paraleti G, et al. D-Dimer testing to determine the duration of anicoagulation therapy. $\mathrm{N}$ Engl $\mathrm{J}$ Med 2006;355:1780-9

[25] Sukrisman L. Trombosis vena dalam dan emboli paru. In: Sudoyo AW, Setiyohadi B, Alwi I (eds). Buku Ajar Ilmu Penyakit Dalam. Edisi IV. Balai Penerbit FKUI, Jakarta. 2006; $802-4$

[26] Setiabudy RD, Sutanto I. Hubungan antara kelainan laboratorium dengan trombosis. Dalam: setabudy RD (ed). Hemostatis. Edisi IV. Balai Penerbit FKUI, Jakarta. 2009;4854

[27] Scarvelis D, Wells PS. Diagnosis and treatment of deep-vein thrombosis. CMAJ 2006; 175( 9):1087-92

[28] Bates. Treatment of deep-vein thrombosis. N Eng J Med 2004;351:268-77

[29] Setiabudy RD. Patofisiologi thrombosis. In: Setiabudy RD (ed). Hemostatis dan trombosis. Edisi IV. Balai Penerbit FKUI, Jakarta. 2009:34-47

[30] Prasad V, Rho J, Cifu A. The diagnosis and treatment of pulmonary embolism: a metaphor for medicine in the evidence-based medicine era. Arch Intern Med 2012;172(12): 955-8 
[31] Buller HR, Cohen AT, Davidson B, et al. Idraparinux versus standart therapy for venous thromboembolic disease. N Engl J Med 2007;357:1094-104

[32] Hartono F, Ismail HD. Insidensi Trombosis Vena dalam Pasca Operasi Orthopedi Risiko Tinggi Tanpa Tromboprofilaksis. J Indon Med Assoc 2011; 61(6): 258-261

[33] Brenner B, Dahl OE, Kakkar AK, et al. Extended duration rivaroxaban versus short-term enoxaparin for the prevention of venous tromboembolism after total hip arthroplasty: a double-blind, randomised controlled trial. Lancet 2008;367: 668-78

[34] Keeling D, Mackie I, Moore GW, Greer IA, Greaves M and British Committee for Standards in Haematology. Guidelines on the investigation and management of antiphospholipid syndrome. BJH 2012;157:47-58

[35] Schierbeck LL, Rejnmark L, Tofteng CL, Stilgren L, Eiken P, Mosekilde L, et al. Effect of hormone replacement therapy on cardiovascular events in recently postmenopausal women: randomised trial. BMJ 2012;345:e6409

[36] Wells PS, Forgie MA, Rodger MA. Treatment of Venous Thromboembolism. JAMA 2014;311(7):717-28

[37] Büller HR, Décousus H, Grosso MA, Mercuri M, Middeldorp $\mathrm{S}$, Prins $\mathrm{MH}$, et al. Edoxaban versus Warfarin for the Treatment of Symptomatic Venous Thromboembolism. N Engl J Med 2013;369:1406-15

[38] Beckman MG, Hooper WC, Critchley SE, Ortel TL. Venous Thromboembolism. Am J Prev Med 2010;38(4S): S495-S501

[39] Prandoni P. Venous thromboembolism and atherosclerosis: is there a link?. J Thromb Haemost 2007;5(Suppl 1):270-5

[40] Israr, YA. Trombosis. Faculty of Medicine University of Riau. Pekanbaru, Riau, 2009
[41] Handin Robert I. Disorders of coagulation and thrombosis. In: Braunwald E, fauci AS, Kasper DL, et al (eds). Harrison's Principle of Internal Medicine. 16th ed. Vol I. Mc Graw-Hill Inc, New York. 2005:680-87

[42] Kearon C, Akl EA, Comerota AJ, Prandoni P, Bounameaux H, Goldhaber SZ, et al. Antithrombotic therapy for VTE disease: Antithrombotic Therapy and Prevention of Thrombosis, 9th ed: American College of Chest Physicians Evidence-Based Clinical Practice Guidelines. Chest 2012;141(Suppl 2):e419S94S

[43] Creager MA, Dzau VJ. Vascular disease of the extremities. In: Braunwald E, fauci AS, Kasper DL, et al (eds). Harrison's Principle of Internal Medicine. $16^{\text {th }}$ ed. Vol I. Mc Graw-Hill Inc, New York. 2005:1486-94

[44] Moser KM. Venous thromboembolism. In: Marino paul L (ed). The ICU Book. $3^{\text {rd }}$ ed. Lippincott Williams and Walkins, New York. 2007:81-103

[45] Lyman GH, Khorana AA, Kuderer NM, Lee AY, Arcelus JI, Balaban EP, et al. Venous Thromboembolism Prophylaxis and Treatment in Patients With Cancer: American Society of Clinical Oncology Clinical Practice Guideline Update. J Clin Oncol 2013;31:2189-204

[46] Buckup K. Venous thrombosis. In: Clinical test for the musculoskeletal system. Klinikum Dortmund, Stuggard. 2004:246-50

[47] Streiff MB, Brady PJ, Grant AM, Grosse SD, Wong B, Popovic T. CDC Grand Rounds: Preventing HospitalAssociated Venous Thromboembolism. Weekly 2014;63(09); 190-3

[48] Oemar H. Pengenalan ekokardiografi dan prinsip dasar. In: Textbook of Echocardiography: Interpretasi dan diagnosis klinik. YMB, Jakarta. 2005: 1-41

[49] Setiabudy RD. Aplikasi D-Dimer di klinik. Informasi Laboratorium Prodia 2009:4: 1-3 